\title{
AgCu Bimetallic Nanoparticles under Effect of Low Intensity Ultrasound: The Cell Viability Study In Vitro
}

\author{
Vladan Bernard, ${ }^{1}$ Ondř̌ej Zobač, ${ }^{2}$ Jiří Sopoušek, ${ }^{2}$ and Vojtěch Mornstein ${ }^{1}$ \\ ${ }^{1}$ Department of Biophysics, Faculty of Medicine, Masaryk University, Kamenice 3, 62500 Brno, Czech Republic \\ ${ }^{2}$ Department of Chemistry, Faculty of Science, Masaryk University, Kamenice 5, 62500 Brno, Czech Republic \\ Correspondence should be addressed to Vladan Bernard; vbernard@med.muni.cz
}

Received 18 August 2014; Accepted 12 December 2014; Published 30 December 2014

Academic Editor: Ganna V. Kalayda

Copyright (c) 2014 Vladan Bernard et al. This is an open access article distributed under the Creative Commons Attribution License, which permits unrestricted use, distribution, and reproduction in any medium, provided the original work is properly cited.

\begin{abstract}
The effects of metallic nanoparticles as cytotoxicity or antibacterial activity are widely known. It is also obvious that ultrasound is one of the most widely used therapeutic modalities in medicine. The effect of application of therapeutical ultrasonic field in the presence of metallic nanoparticles $\mathrm{AgCu}<100 \mathrm{~nm}$ modified by phenanthroline or polyvinyl alcohol was examined on human ovarian carcinoma cells A2780. Metallic nanoparticles were characterized by electron microscopy and by measuring of zeta potential. The cell viability was tested by MTT test. The experimental results indicate a significant decrease of cell viability, which was affected by a combined action of ultrasound field and $\mathrm{AgCu}$ nanoparticles. The maximum decrease of cells viability was observed for nanoparticles modified by phenanthroline. The effect of metallic nanoparticles on human cell in presence of ultrasound exposure was found-a potential health risk or medical advantage of targeted therapy in the future.
\end{abstract}

\section{Introduction}

Ultrasound is widely used in medicine and represents a large percentage of all imaging methods. Ultrasound is also used in therapy. For this reason it is necessary to study the effects of ultrasound on biological objects, although it is generally considered a modality with a very low risk of damage to the patient. The main mechanisms of biological action of ultrasonic energy on biological systems include cavitation, increase in temperature, and mechanical stress [1].

This paper shows that it is possible to observe changes due to ultrasound at the cellular level, for example, as changes in the porosity of cell membranes [2]. It is clear that the state of these structures in specific cases affects the uptake of active substances into the intracellular space. The possibility of targeted delivery of substances into cells using ultrasonic field has been established, both in drugs and in other macromolecular substances $[3,4]$. Targeted synergetic effect of the ultrasound therapy and drugs is used in the sonodynamic therapy [5]. The still unsolved question is the effect of ultrasound on penetration of particles of nanometer scale into the intracellular space. This question is generally associated with particular risks of toxicity of nanoparticles, but it can be seen as a solution to some cancer treatment in the form of targeted therapy. Authors indicating the possibility of targeted nanoparticle delivery stimulated by ultrasound are not numerous and moreover they deal mainly with focused ultrasound of high intensity $[6,7]$. The mechanism of ultrasound action in the cited works is nonthermal and it is explained by the following scheme: the oscillation and destruction of cavitation microbubbles as well as microstreaming and radiation forces are considered to be responsible for the transient rupture of vascular barriers and subsequent increase in the tumor's vascular permeability.

The amount of metallic nanoparticles in the environment and in everyday consumer products increases rapidly. Nanoparticles are included, for example, in cosmetics, clothing, personal care products, and even many foods [8]. For this reason, there are legitimate concerns about the possible interaction between the nanoparticles and the living tissues. The toxicity of some of the particles was demonstrated in both the lower and higher organisms [9-11]. Silver or titanium oxide nanoparticles belong among the frequently mentioned nanoparticles exhibiting toxicity and antibacterial effect $[12$, 13]. 
Bimetallic nanoparticles are also synthesized and examined nanoparticles, for example, nanoparticles made of $\mathrm{AgCu}$ and their modification [14]. AgCu bimetallic particles exhibit toxicity and antibacterial effect which is even much higher than the antibacterial effect of nano-Ag alone [15]. High antibacterial effect was observed for other types of bimetallic nanoparticles obtained $\mathrm{Ag}$ atoms too, for example, binary nanocomposite $\mathrm{Ag} @ \mathrm{Fe}_{3} \mathrm{O}_{4}$ [16].

The aim of experiments was to describe the effect of the combined action of ultrasound and metallic nanoparticles on the viability of human cells. The reason for this action is nonzero probability of presence of nanoparticles in ultrasonic fields used for routine examinations of patients. Considering the existence of already used sonodynamic therapy in the treatment of cancer by cytotoxic drugs it seems useful to certify whether it is possible to achieve similar effect even when using a combination of ultrasonic field and nanoparticles. There is a way open for further use of nanoparticles in medicine, namely, in tumor therapy, after verification of this effect.

\section{Materials and Methods}

2.1. Cell Cultures and Chemicals. Human ovarian carcinoma cell line A2780 was used, obtained from the European Cell Culture Collection. RPMI-1640 medium with L-glutamine (Bio Tech, Ltd., Prague, Czech Republic) supplemented with $10 \%$ fetal calf serum (Bio Tech) and $100 \mu \mathrm{g} / \mathrm{mL}$ streptomycin/penicillin (Bio Tech) was used. The cell line was grown in cell culture flasks in an atmosphere of 95\% air and 5\% $\mathrm{CO}_{2}$ at $37^{\circ} \mathrm{C}$. The cells were detached from glass by trypsin addition (Bio Tech).

2.2. Ultrasound Exposure. BTL-07 therapeutic ultrasound generator (Beautyline Ltd., Prague, Czech Republic) working at a frequency of $1 \mathrm{MHz}$ with a $4 \mathrm{~cm}^{2}$ probe was used as the source of ultrasound. The cells were exposed for $10 \mathrm{~min}$ to the near field of a horizontal beam of continuous-wave ultrasound at intensity of $1 \mathrm{~W} \cdot \mathrm{cm}^{-2}$ in a thermostated $37^{\circ} \mathrm{C}$ water bath. The exposure was carried out in a polyethylene tube fastened to a rotating holder $(3 \mathrm{rpm})$. This experimental set-up provided uniform exposure of the entire volume of cell suspension. Ultrasound intensity and acoustic pressure were measured by means of a calibrated PVDF hydrophone, type MH28-6 (Force Institute Copenhagen, Denmark) by using the calibration protocol.

2.3. Nanoparticles. The AgCu nanoparticles were synthesized in water by chemical coreduction of silver nitrate and copper (II) nitrate hydrate in a particular stoichiometric ratio (metal input equivalent to $\mathrm{Ag}-42$ at $\% \mathrm{Cu}$ in NPs, i.e., eutectic mixture) with 1,10-phenanthroline (polyvinyl alcohol-PVA, resp.) as a surfactant and sodium borohydride as a reducing agent in methanol at $-40^{\circ} \mathrm{C}$ under an inert atmosphere of nitrogen. The product was separated by centrifugation for $10 \mathrm{~min}$ on a centrifuge at $6000 \mathrm{rpm}$. The nanoparticles were washed to remove organic-soluble residues by three or more cycles of resuspending in deionized Millipore water or in PBs for viability experiments.

The size and shape of nanoparticles were characterized by transmission electron microscopy (TEM) Philips CM12 STEM operated at $120 \mathrm{kV}$. Composition of nanoparticles was analyzed by the inductively coupled plasma atomic emission spectroscopy (ICP-OES). Zeta potential was measured by Zetasizer Nano ZS ZEN 3500.

2.4. Experimental Design of Combined Treatment. The cells of A2780 line were incubated for $72 \mathrm{~h}$ after the following modes of treatment:

(i) addition of AgCu nanoparticles only (NPs),

(ii) 10-minute exposure to ultrasound only (us),

(iii) addition of $\mathrm{AgCu}$ nanoparticles and subsequent 10minute exposure to ultrasound (NPs + us),

(iv) 10-minute exposure to ultrasound followed by addition of AgCu nanoparticles (us + NPs),

(v) exposure to ultrasound without addition of nanoparticles (cont).

2.5. Viability Test. The following procedure was used to compare the viability of us, NPs, NPs + us, us + NPs, and control cells: a cell suspension was obtained by trypsinization of cells adhering to the flask bottom. To each well of a 96well plate containing $5 \cdot 10^{4}$ cells in RPMI medium, a calculated volume of NPs stock solution was added to achieve a final concentration of nanoparticles of 9, 0.9,0.09, 0.009, and $0.0009 \mu \mathrm{g} \mathrm{mL}^{-1}$. An equal volume of PBS free of NPs was added to the control cells. No trypsin was added. After incubation for 72 hours, the cells were washed in PBS and evaluated by a standard MTT test of viability [17]. Using an EL800 microplate reader (Bio-Tek, USA) the absorbance of a colour product in each well was recorded at $570 \mathrm{~nm}$. The amount of the colour product is directly proportional to the metabolic activity of mitochondria (i.e., viability) in living cells.

2.6. Statistical Analysis. The absorbance value for each group was converted into cell viability as follows: the median absorbance value of the control group (contr) was taken as $100 \%$; the absorbance of each experimental group was expressed as a percentage of control value, that is, its viability relative to that of the control group. Because of a nonnormal distribution of the values for individual groups, the nonparametric Mann-Whitney $t$-test at a significance level of $P=0.05$ was used. The statistical software STATISTICA 12 was used to calculate the median and the upper and lower quartiles.

The data of viability of each experimental group shown in graphs were obtained from 12 different analyses.

\section{Results}

3.1. Characterisation of Nanoparticles. The size and shape of both $\mathrm{AgCu}$ nanoparticle colloids (containing phenanthroline or PVA) were observed by TEM. The outputs of 


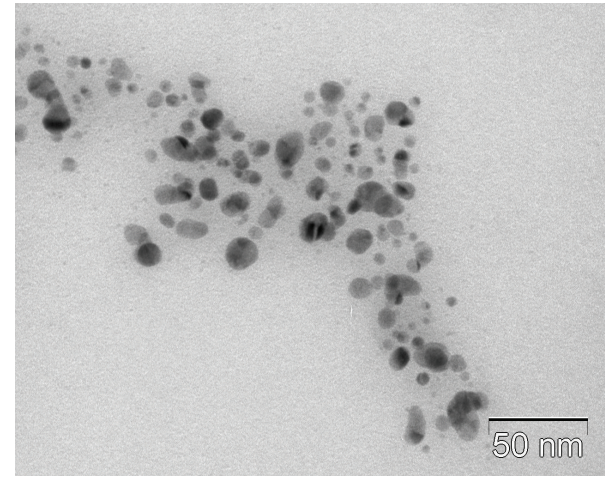

(a)

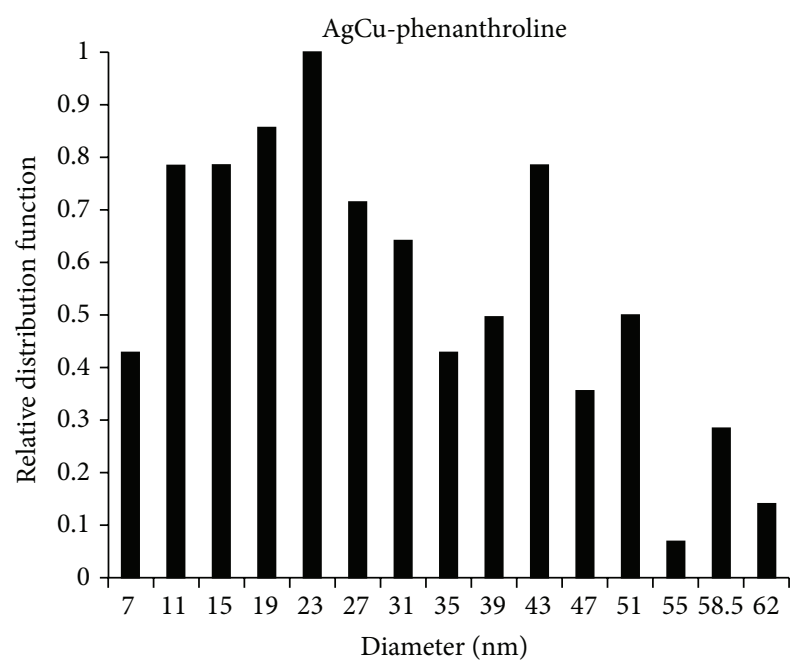

(b)

FIGURE 1: TEM image of nanoparticles of AgCu modified by phenanthroline and their size distribution.

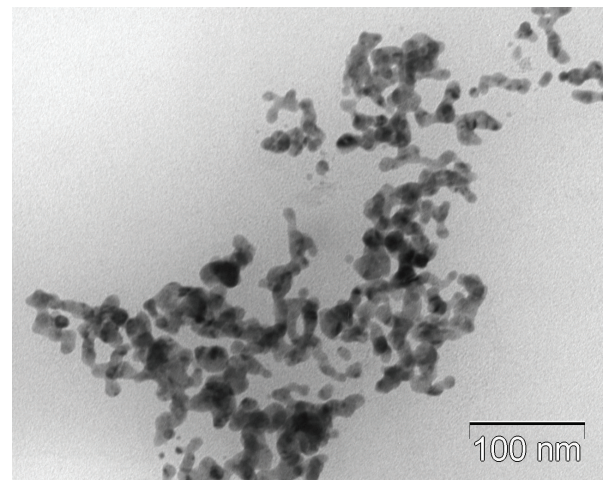

(a)

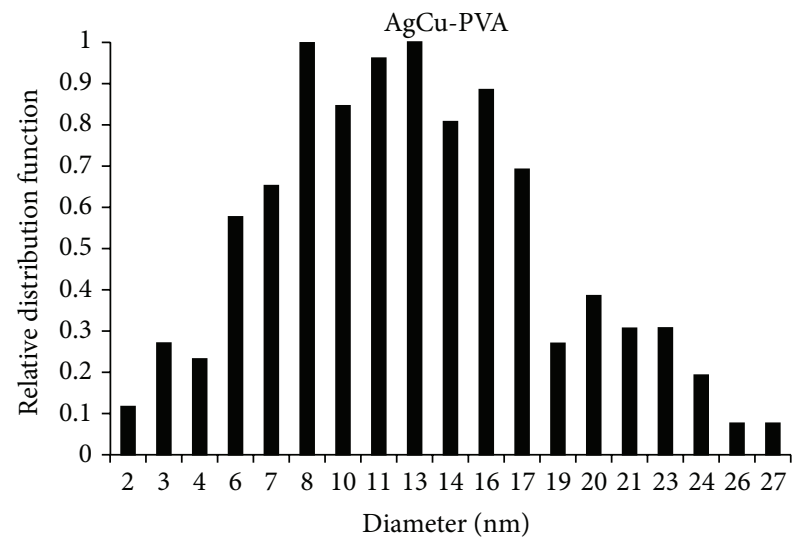

(b)

FIgURE 2: TEM image of AgCu nanoparticles modified by PVA and their size distribution.

this measurement including size distribution histograms are presented by Figures 1 and 2. Both presented TEM images show nanoparticles of size below $100 \mathrm{~nm}$. It is clear that the particles modified by phenanthroline are slightly larger than nanoparticles with PVA - see the maximum values of relative distribution function for $\mathrm{AgCu} /$ phenanthroline (diameter $23 \mathrm{~mm}$ ) and AgCu/PVA (diameter 8 to $13 \mathrm{~nm}$ ). The measured diameters of the AgCu/phenanthroline nanoparticles after the synthesis varied between $7-62 \mathrm{~nm}$ and $2-27 \mathrm{~nm}$ in the $\mathrm{AgCu} / \mathrm{PVA}$.

Zeta potential measured for $\mathrm{AgCu} /$ phenanthroline was $+5.25 \mathrm{mV}$, for $\mathrm{AgCu} / \mathrm{PVA}-5.5 \mathrm{mV}$.

3.2. Cells Viability Test. The viability value of the cells in the experimental groups NPs, us, and us + NPs (with different concentration of nanoparticles in both groups) was compared with the value of control group (contr), and the results are presented in Figures 3 and 4.
The graph in Figure 3 shows the AgCu nanoparticles modified by phenanthroline; the graph in Figure 4 shows $\mathrm{AgCu}$ nanoparticles modified by PVA. Both graphs differ from each other. The first graph shows the nanoparticles with greater potential to affect viability of cells. This fact is evident from the lower value of cell viability for the NPs9 to NPs0.0009 experimental group compared to the same groups in Figure 4. For example, Figure 4 shows almost $100 \%$ viability of cells treated with $0.09 \mu \mathrm{g} \mathrm{mL}^{-1}$ concentration of nanoparticles (NPs0.09 experimental group) and the same concentration of the nanoparticles $\left(0.09 \mu \mathrm{g} \mathrm{mL}^{-1}\right)$ shown in Figure 3 caused a change in viability to less than $80 \%$. The IC50 concentration value was determined from the experimental values obtained in the phenanthroline type of nanoparticles as $0.11 \mu \mathrm{g} \mathrm{mL}^{-1}$ and for the PVA type of nanoparticles as $3.61 \mu \mathrm{g} \mathrm{mL}^{-1}$. It means that the IC50 value for the second type is more than 30 times higher. The viability effect of phenanthroline and PVA alone without 


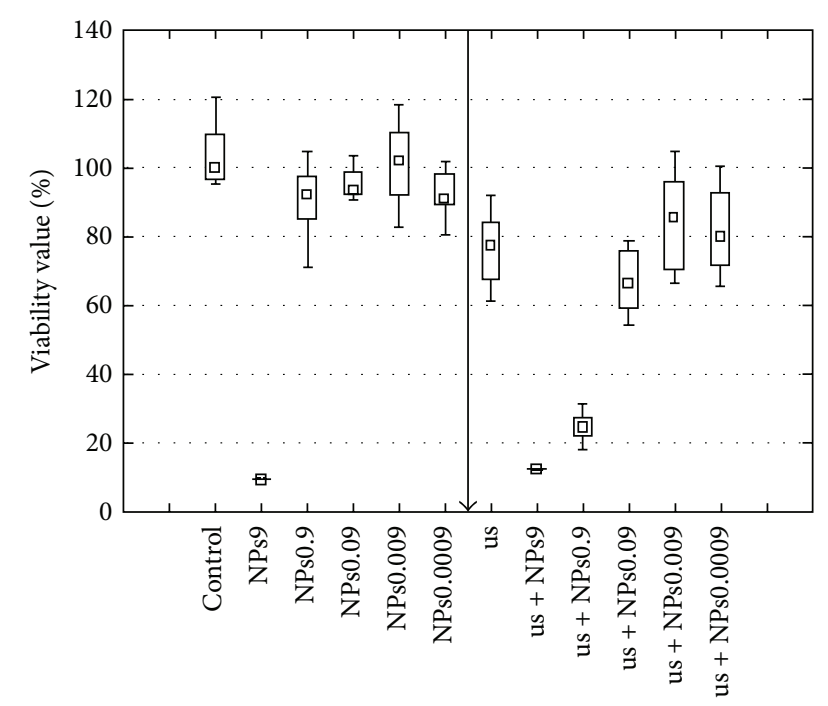

Experimental groups

$$
\begin{aligned}
& \square \quad \text { Median } \\
& \square 25 \%-75 \% \\
& \text { 工 Min.-max. }
\end{aligned}
$$

FIgURE 3: Cell viability at $72 \mathrm{~h}$ of incubation for experiments with $\mathrm{AgCu}$ nanoparticles modified by phenanthroline under the following conditions: us-ultrasound of intensity $1 \mathrm{~W} \cdot \mathrm{cm}^{-2}$, NPs9NPs0.0009-experimental groups affected by NPs stock solution with final concentration of nanoparticles of 9, 0.9, 0.09, 0.009, and $0.0009 \mu \mathrm{g} \mathrm{mL}^{-1}$, contr-control groups, and us + NPs-combination of ultrasound and nanoparticles.

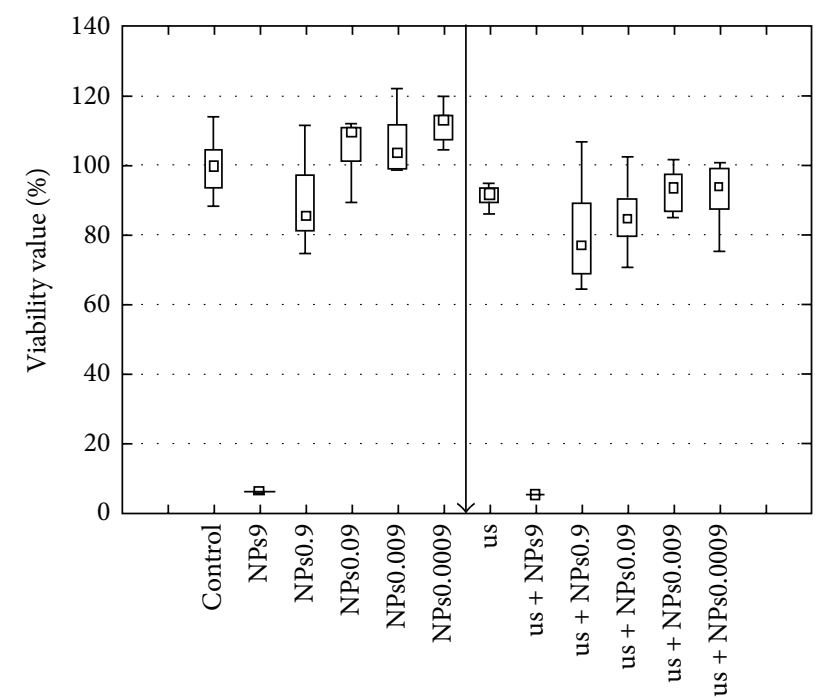

Experimental groups

$$
\begin{aligned}
& \text { Median } \\
& \square 25 \%-75 \% \\
& \text { I Min.-max. }
\end{aligned}
$$

FIgURE 4: Cell viability at $72 \mathrm{~h}$ of incubation for experiments with $\mathrm{AgCu}$ nanoparticles modified by PVA under the following conditions: us-ultrasound of intensity $1 \mathrm{~W} \cdot \mathrm{cm}^{-2}$, NPs9-NPs0.0009experimental groups affected by NPs stock solution with final concentration of nanoparticles of 9, 0.9, 0.09, 0.009, and 0.0009 $\mu \mathrm{g} \mathrm{mL}^{-1}$, contr-control grops, and us + NPs-combination of ultrasound and nanoparticles. nanoparticles on cells was also tested. Greater suppression of viability was found in phenanthroline, as can be expected.

The main results of our experimental work-the study of the combined effects of ultrasound and nanoparticles-are also presented in the graphs on Figures 3 and 4, respectively. The graph shows the decrease of viability for all experimental groups of both suspensions of the nanoparticles in the case of combined application of ultrasound and nanoparticlesexcept for the experimental group us + NPs0.009. The maximal decrease of viability for nanoparticles modified by phenanthroline when comparing nonsonicated and sonicated cells was found in experimental groups NPs0.9 and us + NPs0.9. The analogous comparing for PVA modified nanoparticles shows the maximum decrease of viability for a pair of experimental groups NPs0.09-us + NPs0.09. The difference between the control (contr) group and cells affected by ultrasound (us) alone is about $10 \%$. Values of viability for a combination of ultrasound and nanoparticles (experimental groups us $+\mathrm{NPs}$ ) do not show a simple additive effect (viability decrease value is not equal to the sum of the decreases in viability values of experimental group affected by nanoparticles and by ultrasound separately).

The significant decrease of viability by ultrasound in comparison with viability of cells affected only by nanoparticles is presented in Table 1 . The experimental groups NPs9, NPs0.9, and NPs0.09 are statistically different in comparison with identical experimental groups affected by ultrasound.

\section{Discussion}

The feasibility of the synthesis and modification of nanoparticles are not the subject matter of this paper. It aims to describe the influence of nanoparticles on cells under simultaneous application of ultrasound. This effect has been investigated by using two differently modified suspensions of AgCu nanoparticles. The first version of these nanoparticles was surface modified by phenanthroline (high cell toxicity was expected initially). The second version was nanoparticles modified by PVA (lower cell toxicity was expected). The presented results show almost the same sizes of nanoparticles; a significant difference was therefore only in their surface modification. Just the surface modification seems to be a factor that determines the final toxicity of nanoparticles. It can be stated that the effect of nanoparticles on cell viability is a complex phenomenon, where not only the kind of nanoparticles and their size play a role [18], but also their surface modification. Surface modification of the nanoparticles according to the results of experiments affects not only the aggregation of nanoparticles but also their biochemical and biophysical properties.

The study on cell viability examined the effect of the $\mathrm{AgCu}$ nanoparticles alone, of the ultrasonic field alone, and of their combination. The ultrasonic field was applied with the intensity of $1 \mathrm{~W} \cdot \mathrm{cm}^{-2}$. This intensity value is commonly used in ultrasonic therapy and under our experimental conditions did not produce cavitation effects.

From the obtained data it is clear that the nanoparticles $\mathrm{AgCu} /$ phenanthroline compared with $\mathrm{AgCu} / \mathrm{PVA}$ exhibited higher ability to reduce cell viability. The significant difference 
TABLE 1: Significance of differences in viability values, as assessed by the Mann-Whitney test.

(a) Phenanthroline

\begin{tabular}{lcc}
\hline contr & $\bullet$ & us \\
NPs9 & $\bullet$ & us + NPs9 \\
NPs0.9 & $\bullet$ & us + NPs0.9 \\
NPs0.09 & $\bullet$ & us + NPs0.09 \\
NPs0.009 & + & us + NPs0.009 \\
NPs0.0009 & $\bullet$ & us + NPs0.0009 \\
\hline
\end{tabular}

(b) PVA

\begin{tabular}{lcc}
\hline contr & $\bullet$ & us \\
NPs9 & $\bullet$ & us + NPs9 \\
NPs0.9 & - & us + NPs0.9 \\
NPs0.09 & - & us + NPs0.09 \\
NPs0.009 & + & us + NPs0.009 \\
NPs0.0009 & + & us + NPs0.0009 \\
\hline
\end{tabular}

Symbols: - statistical significance at level $P<0.05,+$ no significance at level $P<0.05$, us: ultrasound of intensity $1 \mathrm{~W} \cdot \mathrm{cm}^{-2}$, NPs9-NPs0.0009: experimental groups affected by NPs stock solution with final concentration of nanoparticles of $9,0.9,0.09,0.009$, and $0.0009 \mu \mathrm{g} \mathrm{mL}{ }^{-1}$, contr: control groups, us + NPs: a combination of ultrasound and nanoparticles.

is evident, for example, between the IC50 concentrations for $\mathrm{AgCu} / \mathrm{phenanthroline} \mathrm{and} \mathrm{AgCu} / \mathrm{PVA}$, since their mutual ratio is given by factor of 30 . These obtained values can be compared with IC50 concentrations for silver or copper nanoparticles published by other authors. For example, Lanone et al. [19] reported silver concentration of $20 \mathrm{mg} \mathrm{mL}^{-1}$ and copper concentration of $5 \mathrm{mg} \mathrm{mL}^{-1}$ in average (however, for different types of cells). Combining ultrasound and nanoparticles causes a decrease in cell viability in comparison with the effect of nanoparticles alone. Thus it could be assumed that it is purely additive effect of nanoparticles and ultrasonic field. Effect of ultrasound on the decrease of cell viability was observed for both variants of $\mathrm{AgCu}$ and for all tested concentrations of these nanoparticles. The obtained data show that the used ultrasound field did not change properties of nanoparticles and their different toxicity was preserved. This is the answer to the question whether the application of ultrasonic field can result in a change of the surface properties of nanoparticles (there is still a big difference between the viability effect of $\mathrm{AgCu}$ phenanthroline and $\mathrm{AgCu}$ PVA) or cause their aggregation and change their size. If the surface modification of nanoparticles is made by ultrasound, changes can be assumed in mutual viability ratio in analogous experimental groups of $\mathrm{AgCu} / \mathrm{phenanthroline}$ and $\mathrm{AgCu} / \mathrm{PVA}$ (e.g., comparisons of viability in the NPs0.9 phenanthroline group with NPs0.9 PVA and us + NPs0.9 phenanthroline with us + NPs0.9 PVA).

The use of ultrasound to promote treatment is well known and called sonodynamic therapy [5]. There is no discussion on using ultrasound to enhance the effect of the drug as in this case. The authors were focused on the benefit (or risk) of ultrasound with respect to its mechanical action on nanoparticles. The possibilities of delivery of small object by ultrasound are documented already [20]. The principle of drug and nanoparticle delivery by ultrasound is not fully explained yet; however, it can certainly differ according to the character of the studied substance. One of the suggested hypotheses in agreement with the results of the present study is based on ultrasound-conditioned "acoustic radiation force induced displacement” of particles [21]. A similar hypothesis involves the hydrodynamic stress that allows sonoporation as described in a review article by Rosenthal et al. [5]. The effects of ultrasound action lead to the formation of pores and increase permeability of membranes [22]. There are also hypotheses for explaining the sonoporation phenomenon from physical point of view, but all based on the existence of oscillating microbubbles.

The authors admitted the existence of all mechanical manifestations of ultrasound on the biological level during the experiments. There was assumption that the effect of cavitation bubbles was limited due to the low ultrasound intensity in this case. Much greater cell affection by combined effect of ultrasound and nanoparticles can be expected when using ultrasound with higher intensity. However, this is undesirable because such ultrasound exposure could be very destructive for cells and tissues due to the cavitation manifestations.

Furthermore, it is necessary to consider the possibility of an effect of ultrasound on the aggregation of nanoparticles. The ultrasonic oscillations can theoretically affect their aggregation. However, the substances adsorbed on the particle surface (phenanthroline, PVA) prevent aggregation of the nanoparticles. It is also known that the viability of cells after combined effect of ultrasound and nanoparticles decreased. This result implies that there was probably no aggregation of nanoparticles during the application of ultrasound.

\section{Conclusion}

The results of experiments show that the toxicity of nanoparticles is determined not only by the selected type of metal, but also by its surface modification. Nanoparticles modified by phenanthroline reduce the cell viability of most. Experiments show the greatest reduction of cell viability in the case of a combination of nanoparticles and ultrasonic field. This viability decrease was probably caused by a simple additive effect (independent effect of nanoparticles and ultrasound). An arrangement can be assumed in which nanoparticles and ultrasonic field could be used for targeted action. The safety question of the action of the ultrasonic field in the presence of the nanoparticles in the human body at the same time was answered. There has been found a statistical change in the value of cell viability for the experimental groups affected by nanoparticles alone compared to the more effective action of nanoparticles in combination with ultrasound based on the performed experiments.

\section{Conflict of Interests}

The authors declare that there is no conflict of interests regarding the publication of this paper. 


\section{Acknowledgments}

This project was financially supported by a grant of GACR no. 13-04408P and by Grant GA14-12653.

\section{References}

[1] M. W. Miller, D. L. Miller, and A. A. Brayman, "A review of in vitro bioeffects of inertial ultrasonic cavitation from a mechanistic perspective," Ultrasound in Medicine \& Biology, vol. 22, no. 9, pp. 1131-1154, 1996.

[2] K. Tachibana, T. Uchida, K. Ogawa, N. Yamashita, and K. Tamura, "Induction of cell-membrane porosity by ultrasound," The Lancet, vol. 353, no. 9162, p. 1409, 1999.

[3] S. Mehier-Humbert, T. Bettinger, F. Yan, and R. H. Guy, "Plasma membrane poration induced by ultrasound exposure: implication for drug delivery," Journal of Controlled Release, vol. 104, no. 1, pp. 213-222, 2005.

[4] V. Frenkel, "Ultrasound mediated delivery of drugs and genes to solid tumors," Advanced Drug Delivery Reviews, vol. 60, no. 10, pp. 1193-1208, 2008.

[5] I. Rosenthal, J. Z. Sostaric, and P. Riesz, "Sonodynamic therapy-a review of the synergistic effects of drugs and ultrasound," Ultrasonics Sonochemistry, vol. 11, no. 6, pp. 349363, 2004.

[6] K. Park, "Focused ultrasound for targeted nanoparticle delivery to tumors," Journal of Controlled Release, vol. 146, no. 3, p. 263 , 2010.

[7] K. C. Crowder, M. S. Hughes, J. N. Marsh et al., "Sonic activation of molecularly-targeted nanoparticles accelerates transmembrane lipid delivery to cancer cells through contact-mediated mechanisms: implications for enhanced local drug delivery," Ultrasound in Medicine \& Biology, vol. 31, no. 12, pp. 1693-1700, 2005.

[8] A. Weir, P. Westerhoff, L. Fabricius, K. Hristovski, and N. von Goetz, "Titanium dioxide nanoparticles in food and personal care products," Environmental Science and Technology, vol. 46, no. 4, pp. 2242-2250, 2012.

[9] A. Kumar, A. K. Pandey, S. S. Singh, R. Shanker, and A. Dhawan, "Cellular uptake and mutagenic potential of metal oxide nanoparticles in bacterial cells," Chemosphere, vol. 83, no. 8, pp. 1124-1132, 2011.

[10] V. Matranga and I. Corsi, "Toxic effects of engineered nanoparticles in the marine environment: model organisms and molecular approaches," Marine Environmental Research, vol. 76, pp. 32-40, 2012.

[11] S. Lanone, F. Rogerieux, J. Geys et al., "Comparative toxicity of 24 manufactured nanoparticles in human alveolar epithelial and macrophage cell lines," Particle and Fibre Toxicology, vol. 6, article 14, 2009.

[12] R. P. Singh and P. Ramarao, "Cellular uptake, intracellular trafficking and cytotoxicity of silver nanoparticles," Toxicology Letters, vol. 213, no. 2, pp. 249-259, 2012.

[13] B. Sha, W. Gao, S. Wang, F. Xu, and T. Lu, "Cytotoxicity of titanium dioxide nanoparticles differs in four liver cells from human and rat," Composites Part B: Engineering, vol. 42, no. 8, pp. 2136-2144, 2011.

[14] J. Sopoušek, J. Pinkas, P. Brož et al., "Ag-Cu colloid synthesis: bimetallic nanoparticle characterisation and thermal treatment," Journal of Nanomaterials, vol. 2014, Article ID 638964, 13 pages, 2014.
[15] M. Taner, N. Sayar, I. G. Yulug, and S. Suzer, "Synthesis, characterization and antibacterial investigation of silver-copper nanoalloys," Journal of Materials Chemistry, vol. 21, no. 35, pp. 13150-13154, 2011.

[16] R. Prucek, J. Tuček, M. Kilianová et al., “The targeted antibacterial and antifungal properties of magnetic nanocomposite of iron oxide and silver nanoparticles," Biomaterials, vol. 32, no. 21, pp. 4704-4713, 2011.

[17] T. Mosmann, "Rapid colorimetric assay for cellular growth and survival: application to proliferation and cytotoxicity assays," Journal of Immunological Methods, vol. 65, no. 1-2, pp. 55-63, 1983.

[18] J.-P. Piret, S. Vankoningsloo, J. Mejia et al., "Differential toxicity of copper (II) oxide nanoparticles of similar hydrodynamic diameter on human differentiated intestinal Caco-2 cell monolayers is correlated in part to copper release and shape," Nanotoxicology, vol. 6, no. 7, pp. 789-803, 2012.

[19] S. Lanone, F. Rogerieux, J. Geys et al., "Comparative toxicity of 24 manufactured nanoparticles in human alveolar epithelial and macrophage cell lines," Particle and Fibre Toxicology, vol. 6, article 14, 2009.

[20] J. Wu, J. Pepe, and M. Rincón, "Sonoporation, anti-cancer drug and antibody delivery using ultrasound," Ultrasonics, vol. 44, supplement, pp. e21-e25, 2006.

[21] H. A. Hancock, L. H. Smith, J. Cuesta et al., "Investigations into pulsed high-intensity focused ultrasound-enhanced delivery: preliminary evidence for a novel mechanism," Ultrasound in Medicine and Biology, vol. 35, no. 10, pp. 1722-1736, 2009.

[22] M. Postema, S. Kotopoulis, A. Delalande, and O. H. Gilja, "Sonoporation: why microbubbles create pores," Ultraschall in der Medizin, vol. 33, pp. 97-98, 2012. 


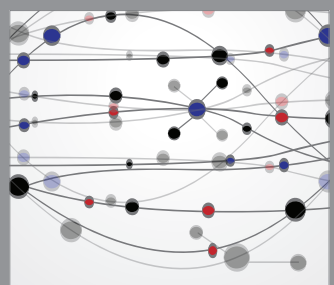

The Scientific World Journal
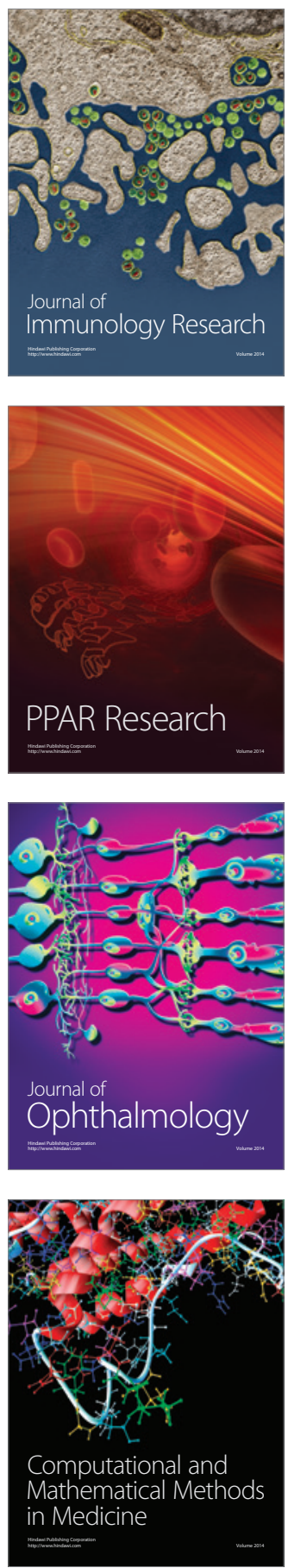

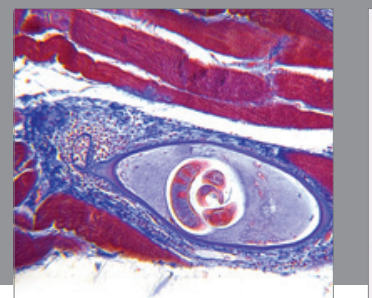

Gastroenterology

Research and Practice
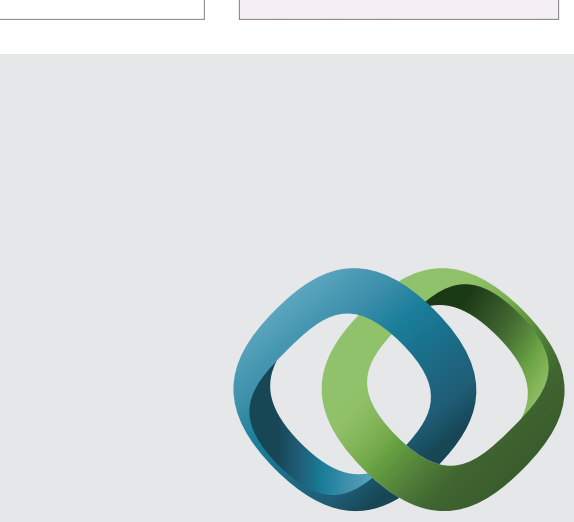

\section{Hindawi}

Submit your manuscripts at

http://www.hindawi.com
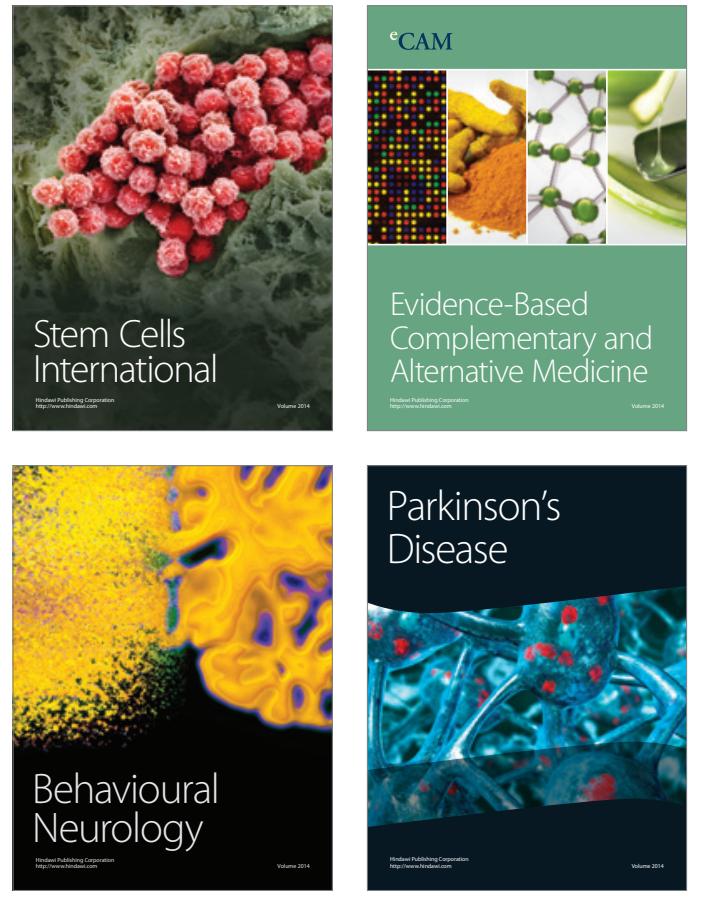
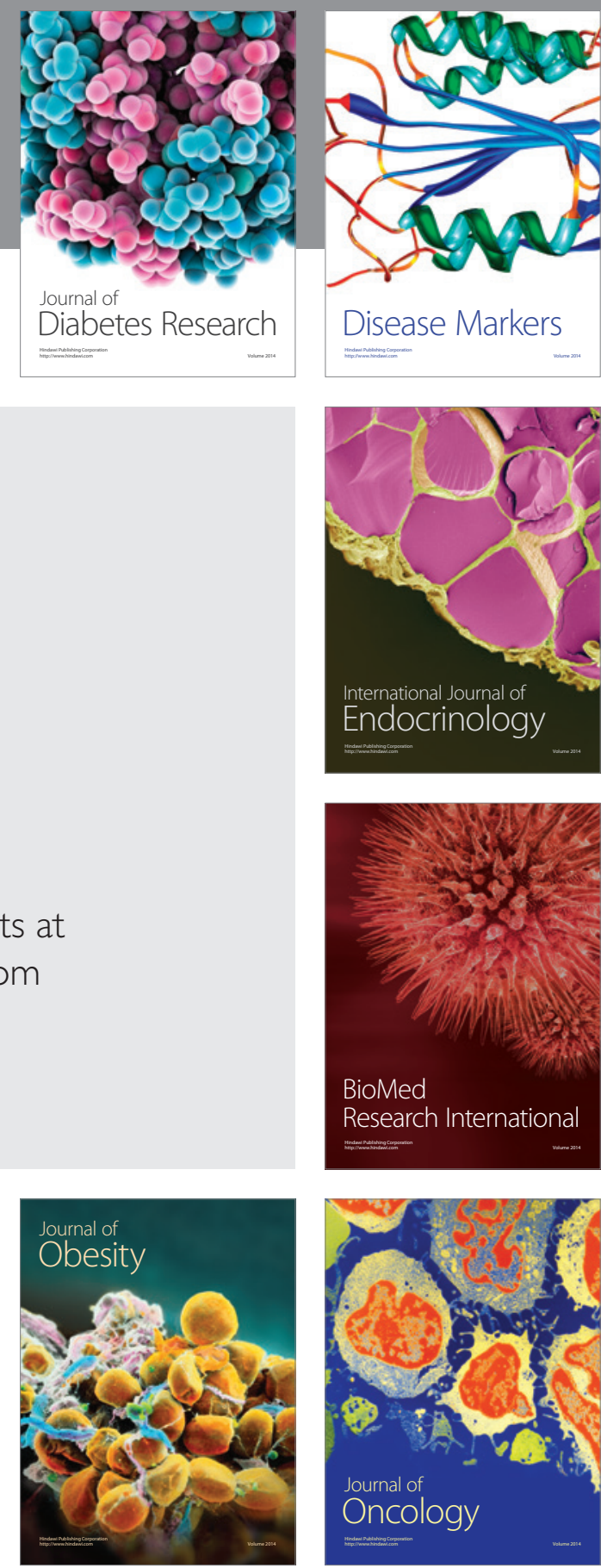

Disease Markers
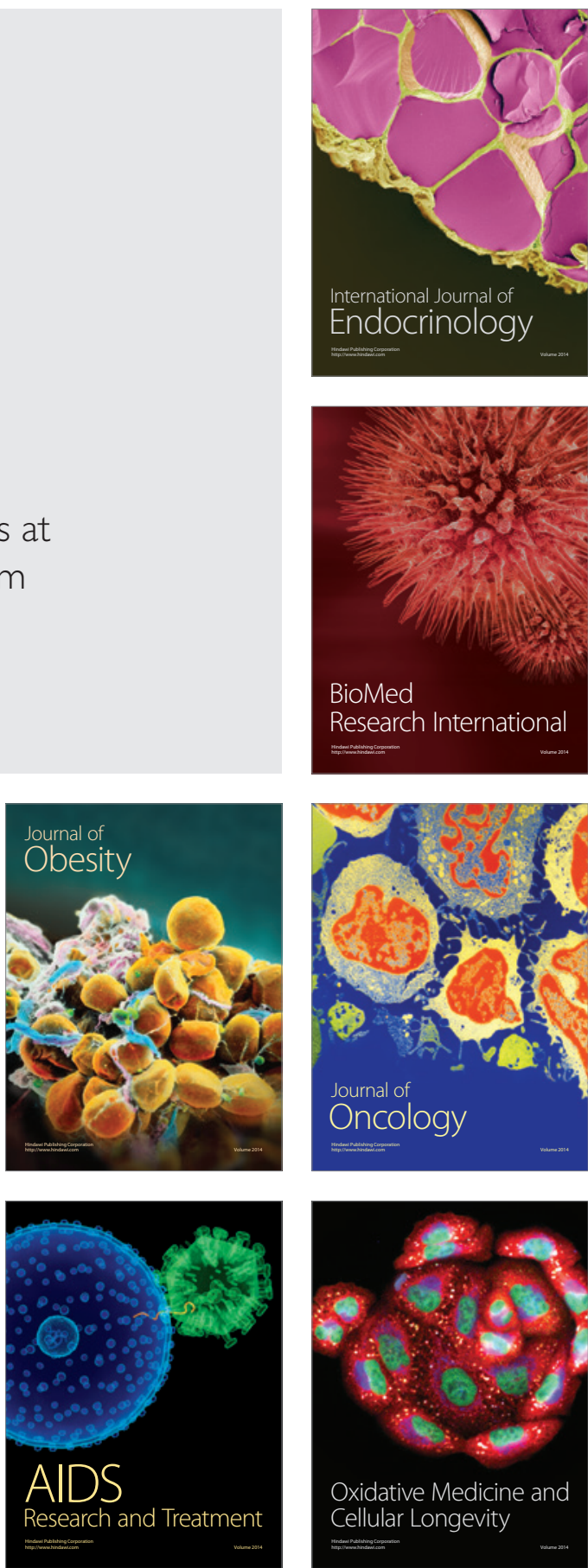